\title{
The study of strategic management improvement in Yemen soft company
}

\author{
Ahmed Al-Halili \\ School of Management Science and Engineering, Dongbei University of Finance and Economics, Dalian, \\ P.R. China \\ Matar aiman \\ L'université de la Rochelle \\ Li Hongxin \\ School of Management Science and Engineering, Dongbei University of Finance and Economics, Dalian, \\ P.R. China
}

\begin{abstract}
Software industry is the core of information industry and the foundation of information-based national economy, and also a strategic industry that decides a country's position in international competition. The Yemeni government has put the development of software industry to a significant part in the national development plan. Yemen Software, a rapid-developing high-tech corporate enterprise, is entering a growing period after years of primitive accumulation. In this key point of development, it is highly necessary for it to make strategic positioning through comparison of internal and external environment opportunities and the advantages and disadvantages of itself. It is also the most important and the most urgent challenge for Yemen to lay its competitive advantage by grabbing the unprecedented developing chance with limited resources and fully taking advantage of its own strengths so as to stand out from the competition. Therefore, it is of much strategic significance to mane comprehensive thinking and studies on the development strategies of this company.

In addition, this paper also makes strategy research on Yemen Software as a subject corporate. In section one, it introduces the importance of studying the development strategies research on Yemen Software as well as the purpose and meaning of this research. The main structure, research methods and technical routes are provided through studying the research condition of this topic. Section two illustrates the nature and features of strategy and introduces the strategy structure and its contents and tasks of this company. Section Three is a general introduction about Yemen Software, including internal operation environment, human resources, market share and resources. Then it analyzes the external macro-environment of this company through the aspects of economy, politics, political law, technical environment and competition environment. In Section four, the author builds a SWOT strategy matrix through the analysis on the advantages, disadvantages, chances and challenges of this company. Section five introduces the Safeguard Measures taken by Yemen Software from four aspects including optimization of organization structure, production strategy, human resources allocation as well as corporate culture. This paper aims to set a development plan for Yemen Software through the strategic analysis and provide learning experience for other similar software companies.
\end{abstract}

Keywords: Yemen Software; strategic management; Yemen; corporate development strategy; SWOT analysis; strategic planning improvement

DOI: $10.7176 / \mathrm{EJBM} / 11-16-12$

Publication date:June $30^{\text {th }} 2019$

\section{Introduction}

In the $21^{\text {st }}$ century, the high-tech software industry plays an increasing important role to the economic development and striving to develop software industry has been a broad sense to governments of all countries and the whole society. Software industry is the core of information industry and the foundation of information-based national economy, and also a strategic industry that decides a country's position in international competition. The Yemeni government has put the development of software industry to a significant part in the national development plan. To support the software industry development, the state government launched the "Policies for Encouraging the Development of Software Industry and Integrated Circuit Industry". Also, many state-level software industry bases 
were established in capital city Sanaa and other places, providing a sound environment for software industry development. In recent years, software outsourcing grows rapidly in Yemen and udders are far from being satisfied of developing and purchasing normal standardized products. A personalized software service market has been formed.

The opportunities of this industry and huge potentials of market bring the best chance for software companies to development as well as fierce competition. With flows of foreign software suppliers and emergence of domestic software companies, the competition in this industry is becoming more and more severe. Yemen Software, being a rapid-developing high-tech corporate enterprise, has entered the growing period after nearly 10 years of primitive accumulation. In this key point of development, it is highly necessary for it to make strategic positioning through comparison of internal and external environment opportunities and the advantages and disadvantages of itself. It is also the most important and the most urgent challenge for Yemen soft to lay its competitive advantage by grabbing the unprecedented developing chance with limited resources and fully taking advantage of its own strengths so as to stand out from the competition. Therefore, it is of much strategic significance to mane comprehensive thinking and studies on the development strategies of this company.

\section{Internal Environment Analysis of Yemen-soft Company}

\subsection{Basic situation of Yemen-soft Company}

For the past two decades, Yemen-soft Company has gained enormous performance and contributed to the economic development of Yemen. The statistical report of the Ministry of Trade and Industry show that the company has generated 40.674 million YR in 1998, and this amount has increased to 80.580 million YR in 2014. However, despite earning the skyrocketing growth in the past period, the Company is currently facing several challenges that affects its performance.

This research focused on the strategic management practice of Yemen-soft Company and compare its performance with that of a major competitor (Blue Horizon) in order to establish a logical interpretation of the findings. In some ways, the study is new to these companies.

\subsection{Internal analysis}

Enterprise internal conditions refer to the human resources, internal resources, corporate culture and enterprise management status and other strategic elements of the enterprise internal. Enterprise internal conditions can also be an internal resource, the enterprise strategy must also be suited to the various resources of the enterprise, the development of enterprises and also to the external environment.

\subsubsection{Human resources}

Yemen soft company has always focused on personnel training. Since 2007, the company has more than 11 MBA employees or related professional knowledge with high skills. Each year the company hires selection of dozens of undergraduate and graduate students. Up to now the company has amassed a total of 104 fulltime workers with an average age of 31 years of which $72 \%$ have higher education. Among the employees two have a doctorate degree, 13 post graduates, 74 undergraduates and 19 have college diplomas in IT. In the development of Yemen-soft for ten years, it has acquired crucial technological developers, of which some have won national awards, and also have gotten international certifications.

\subsubsection{Company culture}

Company culture, that corporate culture, also known as tissue culture, it is a company's values, beliefs, rituals, symbols. It is also the ways of doing things and other content consisting of the company's unique cultural image. In recent years, as the company continues to grow Yemen software development has gradually formed a "loyal to the company, loyal to the occupation, loyal personality," the corporate culture.

Integrity is the value that Yemen-soft holds when dealing with other companies, it's also well represented and held in this manner. When customers purchase a computer equipment Yemen-soft does not raise the price of the standard configuration of the product, which is done in good faith for the sake of the customers.

\subsubsection{Technical resources}

Technology is the basic core ability of the company, and it is the central factor that decides the organization strategy. Technological innovation is the core of today's corporate development strategy part, technological innovation itself is the embodiment of a kind of strategic thought, the choice of product strategy of the choice of technological innovation strategy has direct influence, and the company's technology innovation strategy must obey the 
company's overall strategy. Technological innovation strategy is a part of the overall strategy of the company.

\subsubsection{Financial situation}

As of December 31, 2010, the total assets of the company have reached 3.25 million Yemeni Ryal, than going up year of growth $81.51 \%$, the formation of public also increased by 2.52 times; 5.34 billion Ryal of net assets, compared with the previous year growth $40.37 \%$; assets and liabilities rate for $64.53 \%$, than last year increased by $1.65 \%$. The Incomes and profits; in 2010 the full year incomes reached 45100000 Yemeni Ryal, an increase of $20.89 \%$ over the previous year, total profit of 3425700 Yemeni Ryal. An increase of $40.85 \%$ over the previous year; net profit of 62000000 Ryal, an increase of $70.29 \%$ over the previous year (which attributable to the Net profit of the owners.

The Annual cash inflow reaches around 74000000 Ryal, of 41000000 Ryal in the net profit over the previous year's growth. In 2014, the company achieved a financing profits of 268000000 Ryal, an increase of $54.22 \%$ over the previous year. In 2014, the company invested 36000000 Ryal in the national High-tech industry and achieved an increase of $53.76 \%$ over the previous years. The best profit achievement the Company has achieved since its establishment. From the above can be seen that the company's asset management level is better, but in the future work should be continuous improvement.

\section{Formulation of Yemen-soft Company's development strategy}

\subsection{SWOT analysis of Yemen-soft Company}

\subsubsection{Strength and weakness analysis}

(1)Strengths of Yemen-soft Company

\section{The first is capital advantage.}

Yemen-soft Company has been established for nearly ten years, it can stably get financial and material resources support provided by investors and investment companies, the good investment environment makes Yemen-soft Company obtain good living environment which is a huge advantage for enterprises. Compared with competitors, Yemen-soft Company has advantaged development soil under the support of investors.

\section{Second is brand advantage.}

As an enterprise which has run in Yemen for nearly 10 years, Yemen-soft Company has been recognized by more customers, when new products are launched, it has positive influence and obvious brand effect. Due to the lag of domestic economic development, similar scientific and technologic software companies are less, so competitive environment is relatively not so fierce. Therefore, a lot of products are more popular.

\section{Third is advanced entrant advantage.}

As an enterprise which has run in Yemen for nearly 10 years, Yemen-soft Company has accumulated human relations related to teaching in the process of taking up occupation in the industry, it has in-depth contact with Yemen's national relevant software and information system, and its products have been directly accepted by the Yemeni government and some big family groups. It has deep understanding of software industry development in recent 10 years in Yemen, and also has appropriate understanding of foreign software industry development and has a wealth of experience accumulation.

\section{The fourth is scientific research innovation.}

Yemen-soft Company has possessed independent scientific research innovation system through nearly 10 years' accumulation, Yemen-soft Company Research institute is an enterprise technology center recognized by the government of Yemen.

Yemen-soft Company's scientific research innovation system takes software research institute as link and market demand as guidance to conduct critical and forward-looking software technology research and development. Software research institute is set up with comprehensive research and development center and independent laboratory. Comprehensive research and development center: software product research and development innovation center, software value-added service research and development center, general product software research and development center.

Independent laboratory: infrastructure laboratory, domestic independent development operating system lab, database lab, laboratory of Internet of things, cloud computing service laboratory, information security laboratory, industry emergency laboratory, etc. 


\section{Fifth is to possess all-around service system.}

Yemen-soft Company has established a nationwide service network, formed a unified system of technical support and after-sales service. In line with the concept of 'software increasing efficiency, service creating value', based on customer demands, Chinese software companies attach great importance to service network and service team construction, and pay attention to improve service quality. In terms of service network, the company gradually sets up service outlets at the beginning of establishment, it has established a three-grade service support system that takes capital Sanaa as center, and branches that have been covered in each city nationwide as service channels combining with company's own characteristic, formed service pattern and service network of 'headquarters supporting regional platforms, regional platforms servicing for various regions', it has unique service advantages.

(2) Weaknesses Yemen-soft Company

\section{The first is that system factors restrict development.}

Yemen-soft Company's development scale expands day by day, but management mode is relatively backward and single, model is increasingly standardized, but because of a lack of advanced technology, the whole company's rules and system are solidified compared with large-scale high-tech listed software enterprises, its institutional framework is complex and is inflexible in operation mechanism, particularly in aspects of selection system and employment system, employee training, motivation system and promotion system, it lacks marketization. It suffers much containment in business process and has certain distance with competitors in terms of capital operation, new project investment, and regular customer maintenance and market development.

\section{Second is complicated business decision process.}

Projects go through fairly complex approval process from start to end, including project approval and examination process, bid inviting and approval process, sales contract review process, purchasing requisition process as well as purchasing contract review process.

\section{The third is the weak collaboration ability of sales team.}

In a team, personal ability is certainly important, but the most important is concerted cooperation between different roles of people in the team so as to achieve expected goal. There is no individualistic heroism in a team and only group who makes effort, divides work and collaborates to achieve common goals. Teams should respect, appreciate, tolerate each other, be equal, trust each other, communicate with each other and be responsible for each other. General projects take at least one year in the whole process of feasibility study, preliminary design, project approval, implementation and bid inviting, just relying on sales personnel's personal ability is not enough, team work and clear division are essential, different roles of people in public relation decision-making chain should respectively divide and conquer and compete for projects finally.

\section{The fourth is not high level of human resource management.}

Human resource management mainly includes: human resource planning, job analysis and orientation, career planning, employee selection, performance appraisal, salary system assessment, incentive mechanism, employee training, employee labor relation management, human resource accounting. Company only informs station position when new employees registering and has no process of introducing each other, this makes new employees very strange to the environment, employees just think in their minds without the guidance of corresponding personnel, this makes employees who just take work be at a loss; on-the-job employees also have no career planning, there is no employee motivation and promotion system, employees just go to work and get off work on time, receive wages on time and do their own things, they are loose without energy, cohesion and even fighting capacity.

\section{The fifth is high talent liquidity.}

On one hand, the leadership of Yemen-soft Company is general centralized management no matter in early project tracking or final implementation of project, managing to the end and being specific to some project details, this kind of management style will make employees feel that leaders don't trust him and personally bother about everything, if things go on like this, distrust between employees and leaders will appear, sales personnel are not willing to track projects and technical personnel that take charge of project implementation are also not willing to do projects, talents will drain finally.

Competition among software companies is generally technological competition, namely talent competition, many companies will hire people away from competitors by virtue of high salary and high position, and many employees will leave. 


\section{The sixth is inadequate software project implementation capacity.}

Because frequent flow of technical personnel will bring certain effect to software development project process, followed developers take very long time to be familiar with software which affects software development cycle, coupled with company leadership's lack of overall project mastering, they will repeatedly do some idle work in project implementation process, lengthen software development cycle and increase labor cost, and also affect customer satisfaction.

\subsubsection{Opportunity and threat analysis}

(1) Opportunities

One is that the country creates a good policy environment for software industry development and carries on major support on software industry.

Under the direct concern and instruction of Yemeni government, it has issued a lot of policies to support Yemen's software enterprise development and has determined recent strategic target of software industry, this will certainly bring a new upsurge for Yemen's software industry development. Seen from national macroscopically development strategy, software industry will be one of the industries majorly supported by the country in the future, this provides an unprecedented development stage for Yemen's software industry development.

Second is that national economy informatization speeds up to provide new opportunities for the development of software industry and market.

The third is that social capital investment in software industry accelerates growth.

The fourth is that economic globalization brings new opportunity to software industry development.

Worldwide rapidly developed information tide provides a huge market for software industry base, along with the constant emergence of information software areas, Yemen's software industry is facing a rare international opportunity. Since the reform and opening-up, a large number of overseas Chinese and overseas students return for pioneering work; a large number of foreign companies also join in Yemen. Although their arrival has influence on domestic enterprises in talent competition, in the long run, their technical strength and management level have played a positively promoting role in Yemen's software industry.

(2) Threats

\section{First, powerful competition from other software vendors.}

As the acceleration of international capital flow scale and speed, international software outsourcing market scale increases, outsourcing business develops towards Asia-Pacific region. Foreign software giant sets foot in Yemen's software market and brings advanced technology and management experience.

\section{Second, government's limited regulatory mechanism level.}

Yemen's private enterprises currently account for $65 \%$ of overall software enterprises, departments in charge differ in thousands of ways, on one hand, they can't establish effective quality assurance and supervision system for industry, on the other hand, they also couldn't provide better services for enterprises, guide and cultivate software enterprises from perspective of overall situation 'A Game of Chess'. This is also an important reason that causes 'small, scattered and weak' Yemen software enterprises. The reason why India's software industry is successful lies firstly in energetic support and support of various preferential policies from government, while in Yemen, although it has been actively advocating, due to system, it still lacks support policies that are conducive to software enterprise development, such as the insufficiency of establishment of software enterprise risk investment mechanism and implementation of software property right protection mechanism, etc.

\section{The third is that micromanagement is in urgent need of strengthening.}

We can't ignore that software enterprises themselves are also facing problems in management and operation, including the following four aspects: market operation and management tends to go to two extremes. To overcome the above two phenomena, it is necessary to strengthen market research, market evaluation and economic evaluation strength, strengthen and perfect marketing methods and marketing system, and implement benefit balance management between markets and products, etc.

\subsection{Strategy matrix of Yemen-soft Company}

According to the above SWOT analysis, we can see that Yemen-soft Company obtains a good survival and development environment, but if not quickly practicing aiming at own disadvantages and developing own ability of technology and business development, while excessively relying on existing advantages, Yemen-soft Company 
will eventually lose market survival and competition ability. Therefore, the rational analysis of Yemen-soft Company's strengths, weaknesses, opportunities and threats, and conducting effective matching and combination are helpful for company to recognize internal and external environment as well as reasonably making strategic choice. Yemen-soft Company's SWOT strategic matrix analysis is shown in table 3.1 below.

Subdividing according to SWOT analysis method, Yemen-soft Company's strategic combination includes the following four kinds:

(1) Strength + Opportunity (SO) combination.

This combination can be said to be the most ideal combination in strategic combination. In the combination, enterprises are faced with good development trend, namely opportunities and advantages achieve ideal combination. Enterprises can effectively use and combine own resources with opportunities provided by external environment together so as to gain competitive advantages. Yemen-soft Company's current advantages are brand advantage and advanced entrant advantage, while opportunities provided by external environment are prospects for broad space of software industry development and new software product development, if it can effectively combine the two and fully mobilize company's existing resources, it will certainly boost company to complete its mission and ultimate goal.

(2) Weakness + Opportunity (WO) combination.

In the combination, enterprises are faced with good external environment and possess great market opportunity, but due to obvious internal disadvantages, enterprises' ability of using opportunities is restricted. Enterprises should make the most of recognized opportunities to make up for their deficiencies, but they cannot blindly invest. For Yemen-soft Company, its disadvantages are a series of problems such as low work efficiency, limited marketing ability, being unable to protect talents, research and development efficiency, etc. caused by system problem, so the company should also calmly analyze with respect to market opportunities.

(3) Strength + Threat (ST) combination.

Enterprises in this area possess stronger internal advantages, but there are many unfavorable factors in external market environment. Seen from above analysis of Yemen-soft Company's internal and external environment, external threats do exist, but they haven't reached uncontrollable degree, the author has reasons to believe that company can make up for corresponding threats in external environment by virtue of its internal advantages.

(4) Weakness + Threat (WT) combination.

This is the worst combination state, so to speak, enterprises under the situation are faced with external worries and internal troubles, and they must make a choice of retreat or transformation. Speaking of Yemen-soft Company's situation, combination of weaknesses and threats is not enough to force company to make a choice of retreat or transformation, company still has opportunity of further development as long as it can make right decisions, give full play to own advantages and effectively use market opportunities.

\subsection{Yemen-soft Company's design of development strategy}

\subsubsection{Strategic positioning}

Yemen-soft Company is mainly engaged in software development of IT industry of computer system integration and related diversified development strategy. Implementing focus strategy and low cost strategy, maintaining coordinated development of company technology, sales and service links, providing users with high quality products and high quality service by virtue of excellent management, and continuously expanding market share so as to make enterprise achieve sustainable sales growth and profit growth, create company's outstanding corporate culture, take the combined road of efficiency and benefit, strive for standing on a higher level of management, benefit and scale within three years, and eventually become domestic first-class IT enterprise is the long-term goal of Yemen-soft Company. While ensuring interests of shareholders, company and employees, the company returns society, and makes biggest contribution to human progress and society's harmony \& prosperity. Strategic goals of company are not only enterprise's strategic starting point and basis, but also results that shall be achieved by enterprise's strategy implementation. The company is people-oriented, it attaches importance to talents, respects talents, establishes a healthy and progressive corporate culture, cultivates and establishes the habit of continuously innovated ability, and it is dedicated to exerting the biggest efforts to Yemen's information industry especially development of software industry.

\subsubsection{Competitive strategies}

Through SWOT strategic matrix analysis of Yemen-soft Company in above table 3.1, it can be seen that company's current position of development is in the quadrant of SO strategy. We should make full use of internal advantages and external opportunities, seize all favorable conditions, constantly develop marketable products, quickly develop 
target markets, expand market shares and form competitive advantages.

(1) March to high-end fields of industry products based on maintaining core technology competitiveness. Yemensoft Company should take advantage of policy advantages and policy support for capturing its own position, aim its development goals at high-end product fields. With the development of informationization, perfection of enterprise information management and overall quality improvement of enterprise's information personnel, highend products will be a development trend.

(2) Implement talent strategy. Accelerate the construction of software talent team, reduce brain drain. Improve management and business environment, create a relaxed work environment that respects knowledge, attaches great importance to talents and gives play to talents' ability. Establish employee shareholding system, stock option system, annual salary system and other flexible incentive mechanisms to make knowledge and ability participate in distribution as capital, and live up to retaining people with career, emotion and treatment.

(3) Implement brand strategy. Integrate resources in aspects of technology, software quality and service, etc. so as to build a well-known brand with obvious competitive advantages at home and abroad market.

(4) Inject new management concept and take internationalized development route. If an enterprise wants to have long vitality, it is necessary to keep pace with the times, develop itself, take internationalized development route and break previous ways of thinking, to achieve these, it has to free itself ideologically, the first is to change software design, it should inject advanced management concept and take introductory enterprise management as principle, but not just passively adapting to enterprise management. The second is to pay attention to system integration and operability of interface in terms of function module, it must conform to international thinking. Finally, it can't aim at enterprise's personnel service mode, but can only attach importance to take enterprise this legal entity as object to cultivate enterprise management concept for adapting to needs of fierce market competition and improving competitiveness of enterprise.

Based on the adoption of these strategies, Yemen-soft Company should combine with the actual situation of its own whole situation of intellectual property, industry characteristics, region, enterprise culture and organizations, etc., make full use of its advantages to resolve disadvantages, fully use opportunities from external environment to avoid strikes caused by challenges. At the same time, according to different customers, different markets and different competitors, it should take different strategic decisions, only in this way can it is highly effective in the future development road and truly become a leading enterprise in Yemen's same industry competitors.

Table 3.1 Yemen-soft Company's SWOT Analysis Matrix

\begin{tabular}{|c|c|c|}
\hline & $\underline{\text { Strengths }}$ & Weaknesses \\
\hline SWOT Analysis & $\begin{array}{l}\text { One is capital advantage. } \\
\text { Second is brand advantage. } \\
\text { Third is advanced entrant advantage. } \\
\text { Fourth is scientific research innovation. } \\
\text { Fifth is to possess all-around service system. }\end{array}$ & $\begin{array}{l}\text { One is that system factors restrict } \\
\text { development. } \\
\text { Second is complicated business decision } \\
\text { process. } \\
\text { Third is weak collaboration ability of sales } \\
\text { team. } \\
\text { Fourth is not high level of human resource } \\
\text { management. } \\
\text { Fifth is high talent liquidity. } \\
\text { Sixth is inadequate software project } \\
\text { implementation capacity. }\end{array}$ \\
\hline Opportunities & SO Strategy & WO Strategy \\
\hline $\begin{array}{l}\text { first is that the country creates a good policy } \\
\text { environment for software industry } \\
\text { development and carries on major support on } \\
\text { software industry. } \\
\text { Second is that national economy } \\
\text { informatization speeds up to provide new } \\
\text { opportunities for the development of software } \\
\text { industry and market. } \\
\text { Third is that social capital investment in } \\
\text { software industry accelerates growth. } \\
\text { Fourth is that economic globalization brings } \\
\text { new opportunity to software industry } \\
\text { development. }\end{array}$ & $\begin{array}{l}\text { First is to take advantage of brand advantage } \\
\text { and national policy support to energetically } \\
\text { develop scientific research innovation and } \\
\text { develop new products. } \\
\text { Second is to use all-around service system to } \\
\text { quickly seize domestic low-end product } \\
\text { market. }\end{array}$ & $\begin{array}{l}\text { First is to introduce foreign advanced } \\
\text { management mechanism to perfect } \\
\text { company's existing management system } \\
\text { and get rid of bad habits. } \\
\text { Second is to improve team's marketing } \\
\text { ability and writing ability. } \\
\text { Third is to purposefully cultivate talents. }\end{array}$ \\
\hline Threats & ST Strategy & WT Strategy \\
\hline $\begin{array}{l}\text { One is powerful competition from other } \\
\text { software vendors. } \\
\text { Second is government's limited regulatory } \\
\text { mechanism level. } \\
\text { Third is that micromanagement is in urgent } \\
\text { need of strengthening. }\end{array}$ & $\begin{array}{l}\text { First is to further improve service level and } \\
\text { build brand competitiveness. } \\
\text { Second is to develop new products through own } \\
\text { experience. }\end{array}$ & $\begin{array}{l}\text { First is to perfect company's management } \\
\text { establishment. } \\
\text { Second is to carry on diversified operation. } \\
\text { Third is to give up some bad business. }\end{array}$ \\
\hline
\end{tabular}




\section{Implementation of Yemen-soft Company's Development Strategy}

In strategic management, strategic implementation is the action phase of strategic management, it is a continuation of strategic choice. Yemen-soft Company's development strategy is to clear about company's development direction, only direction is not enough, it must carry out company's development strategy. Strategy implementation process is to timely adjust development plan according to company's macroeconomic environment, market environment, competitive environment, industry environment and development change situation. This requires strategy implementation to possess strong safeguard measures to achieve company's strategy implementation.

\subsection{Optimization of organizational structure}

Yemen-soft Company has established specialized development strategy, this indicates company management layer's determination of developing company by taking low-end software products as leading business for a long time. And organizational structure construction is the foundation of enterprise's system reform, delivering and processes organizational structure can greatly promote improvement of enterprise's management level, help enterprises to complete effective operation and achieve enterprise's strategic goals. In order to ensure the effective implementation of Yemen-soft Company's specialized development strategy, specially put forward the following measures for organizational structure optimization.

(1) Change management ideas and realize moving down of decision-making power

Modern enterprises still stay in tactics phase of a mountain of paperwork and a sea of meetings, enterprise managers tend to directly decide plans at the meeting, and can't get a very good effect, this is mainly because that enterprise managers themselves are not experts in professional fields, they are also hard to carry on comprehensive grasping of data, the more serious is that this is likely to directly suppress specific creators' creativity, therefore, enterprise managers should not concern, examine and approve and decide decision schemes, but to concern that whether work process is conducive to generation of best solutions.

(2) Uniformly allocate resources and realize optimal integration of resources

Enterprise's management layer is helmsman of enterprise development, reasonable and effective distribution of enterprise's existing resources to maximize its role can help enterprises to get twofold results with half the effort in the process of pursuing strategic goals. Moreover, optimal integration of resources also includes evaluation on company's existing resources and enterprise strategy to guarantee enterprise's cruising ability in carrying out development strategy.

\section{(3) Change information flow and realize straight transmission of information}

Enterprise managers certainly need to grasp data of guiding nature, but generally speaking, enterprise managers should not know too much about professional information material, but to facilitate straight transmission of information, each link in the overall process should conduct self-control input and output information quality to avoid phenomena of lost, misunderstanding and deviation in information transmission, internal and external sole interface pattern can't necessarily achieve best effect, the key is clarity and definition of various information interfaces.

(4) Promote collaboration between departments and realize united pace

Current enterprise organizations' common problem is less communication between different departments, they only complete internal tasks of departments and don't care about situations of other departments. For example, many enterprise managers think that research \& development department and sales department, or sales department and finance department, etc. are two pairwise independent departments, they do not need to communicate and exchange, in fact, the idea is wrong and outdated, all departments within enterprises are constituent parts of enterprise, detachment between each other's work will directly affect enterprise's development pace. To promote effective cooperation between departments is conducive to company's uniform implementation of strategy and can greatly improve work efficiency.

\subsection{Products Improvement}

\subsubsection{Upgrading Existing Products}

Yemen-soft Company is growing high-tech industry. Currently, the Company has independent R\&D products, basic software products, general software products and high-end application products, which are in leading position in the industry. However, competing companies are actively imitating similar R\&D products to compete with independent products of Yemen-soft Company, which requires Yemen-soft Company to improve their own independent product technologies and services, so as to realize difference-making competition, increase product sales and increase market share. The Company needs to go to the customer site, listen to the improvement 
suggestions of customers, deeply explore the customer's needs, grasp the direction of product upgrading and improve the product quality of the Company. Yemen-soft Company continuously improves its own independent products, which cannot only secure market share, but also allow customers to buy upgrade services, to achieve the purpose of long-term cooperation with customers.

\subsubsection{Strategic alliances to promote new product development}

The independent R\&D software products of the Company have a certain market share in the software market. However, it is unlikely to improve the market share and substantially increase the performance in the short term by expanding the market channel. Therefore, Yemen-soft Company can establish strategic cooperation relations through cooperation with its upstream and downstream software companies, develop product functions for the low-end market on its own independent research and development platform, reduce the unit development cost and introduce products for the low-end market. Thus, on one hand, open up the low-end market to make products get more market share, on the other hand, curb the development of competitors.

\subsubsection{Merging and Purchasing Relevant Software Products}

Integrate the industrial chain and combine with products of upstream and downstream software companies, Yemensoft Company can expand the product line of software companies through the way of software merger and acquisition. The merger and acquisition of fully competitive products can improve the market share and sales volume of the Company. Yemen-soft Company also considers merging and purchasing software companies related to software of the Company and focusing on customer group in different industries.

\subsubsection{Software Project Quality Management}

Yemen-soft Company has not only its own independent software products, but also the application software projects according to the industry. According to the software project, develop a full set of quality management control measures. The implementation of measures in the early, medium and late stage of project implementation can ensure the implementation quality of the project. The early implementation: develop detailed technical solutions and configuration documents, etc.; conduct detailed and careful arrangement and planning on the implementation progress and human resources of the whole project, form integrated project implementation plan; develop the corresponding test plan according to the user's requirements.

\section{Conclusion}

On the base of researching the modern enterprise development strategy theory, this paper combines the current development situation of Yemen-soft Company, systematically analyzes the existing problems in the original development strategy of Yemen-soft Company, including the current internal and external environment of company, combined with the actual situation, then proposes the new company development strategy, and conduct detailed discussion on the implement and control of strategy.

Firstly, with the continuous deepening of informatization society process, and the trend that government makes efforts to develop software industry, Yemen-soft Company can utilize its own brand advantages and the full range of market services to continue to develop new products, open up new markets and improve its competitiveness. Even this field has not been paid attention, with the continuous improvement of technology, network, and other related technologies, it is sure to bring great value-added space for company.

Secondly, a set of excellent enterprise development strategy can help the enterprise to remain enduring competitive in the industry competition, and finally obtain profit. Through the detailed analysis on the internal and external environment of Yemen-soft Company, it formulates a set of professional development strategy for company, so as to further enhance the company's core competitiveness.

Thirdly, through the research on product development, resource optimization, market development and other aspects of Yemen-soft Company, it proposes the related suggestions on the implement of company's professional development strategy. But all the strategies will occur some deviations during the implementation process, in order to ensure the strategy can be effectively implemented, then develop along the expected trajectory, it must conduct control on the strategy, and correct the deviations in time.

Due to the limited ability of author, and the limitation on the control of overall situation, there are many deficiencies in the depth of analysis, the formulation of strategy and other aspects, so all the experts, reviewers please make the guidance and correction. 


\section{References}

1. Yang Hongjuan, Zhang Jing. The Strategies of Advancing the Cooperation Satisfaction among Enterprises Based on Low Carbon Supply Chain Management[J]. Energy Procedia, 2011, 5: 1225-1229.

2. Henning Engelke, Stefanie Mauksch, Inga-Lena Darkow, Heiko A. von der Gracht. Opportunities for social enterprise in Germany - Evidence from an expert survey[J]. Technological Forecasting and Social Change, 2015, 90: 635-646.

3. Harpreet Singh, Ardavan Amini, Luis Hernandez-Munoz. An Enterprise Systems Model to Deliver Innovation in the Healthcare Industry Based on Cognitive and Social-Tech Engineering[J]. Procedia - Social and Behavioral Sciences, 2015, 195(3): 1705-1714.

4. Ayşenur Erdil, Hikmet Erbıyık. Selection Strategy via Analytic Hierarchy Process: An Application for a Small Enterprise in Milk Sector[J]. Procedia - Social and Behavioral Sciences, 2015, 195: 2618-2628.

5. Jenny Leonard, Helen Higson. A strategic activity model of Enterprise System implementation and use: Scaffolding fluidity[J]. The Journal of Strategic Information Systems, 2014, 23(1): 62-86.

6. Alfredo Jiménez, Juan Bautista Delgado-García. Proactive management of political risk and corporate performance: The case of Spanish multinational enterprises[J]. International Business Review, 2012, 21(6): 1029-1040.

7. Konstantinos Poulis, Mo Yamin, Efthimios Poulis. Domestic firms competing with multinational enterprises: The relevance of resource-accessing alliance formations[J]. International Business Review, 2012, 21(4): 588-601.

8. Harcharanjit Singh, Rosli Mahmood. Aligning Manufacturing Strategy to Export Performance of Manufacturing Small and Medium Enterprises in Malaysia[J]. Procedia - Social and Behavioral Sciences, 2014, 130: 85-95.

9. Sefer Şener, Mesut Savrul, Orhan Aydın. Structure of Small and Medium-Sized Enterprises in Turkey and Global Competitiveness Strategies[J]. Procedia - Social and Behavioral Sciences, 2014,150: 212-221.

10. Chung-Hsing Yeh, Yan Xu. Managing critical success strategies for an enterprise resource planning project[J]. European Journal of Operational Research, 2013, 230(3): 604-614.

11. Marcin Piątkowski. Integration of Enterprises on the Example of Clusters in Poland[J]. Procedia - Social and Behavioral Sciences, 2015, 181: 313-320.

12. Betty Chang, Chin Kuo, Chih-Hung Wu, Gwo-Hshiung Tzeng. Using Fuzzy Analytic Network Process to assess the risks in enterprise resource planning system implementation[J]. Applied Soft Computing, 2015, 28: 196-207.

13. Ting Wang, Bing chuan Xin, Li juan Qin. AHP-Based Capacity Evaluation of Enterprise Development[J]. Procedia Engineering, 2011, 15: 4693-4696.

14. Anna Witek-Crabb. Business Growth Versus Organizational Development Reflected in Strategic Management of Polish Small, Medium and Large Enterprises[J]. Procedia - Social and Behavioral Sciences, 2014,150: Pages 66-76.

15. Samuel B. Moore, Susan L. Manring. Strategy development in small and medium sized enterprises for sustainability and increased value creation[J]. Journal of Cleaner Production, 2009, 17(2): 276-282.

16. Zhe Xu, Jay Ramanathan. Thread-based probabilistic models for expert finding in enterprise Microblogs[J]. Expert Systems with Applications, 2015, 113: 857-869.

17. Bong-Soo Lee, Byung S. Min. Exchange rates and FDI strategies of multinational enterprises[J]. Pacific-Basin Finance Journal, 2011, 19(5): 586-603

18. Anvar Gumerov, Andrey Sarkin, Boris Averyanov. Elaboration of Enterprise Development Strategy in Real Sector of Economy Using Quality Management Tools[J]. Procedia Economics and Finance, 2014,15: 687-694.

19. Rana Mostaghel, Pejvak Oghazi, Hooshang M. Beheshti, Magnus Hultman. Strategic use of enterprise systems among service firms: Antecedents and consequences[J]. Journal of Business Research, 2015, 68(7): 1544-1549.

20. Francesco Ciampi. Corporate governance characteristics and default prediction modeling for small enterprises. An empirical analysis of Italian firms[J]. Journal of Business Research, 2015,68(5): 1012-1025.

21. Claudia Ogrean. Coordinates and Dynamics of the Relationships between Multinational Enterprises and Economic Development - A Theoretical Approach[J]. Procedia Economics and Finance, 2013, 6: 319-327.

22. Yuan Sun, Samar Mouakket. Assessing the impact of enterprise systems technological characteristics on user continuance behavior: An empirical study in China[J]. Computers in Industry, 2015, 70: 153-167.

23. I-Hsuan Cheng. Remodelling and reconceptualising skills development in Cambodia: How are social enterprises preparing young people for successful transitions between learning and work? [J]. International Journal of Educational Development, 2015, 43: 134-141.

24. Xuemei Jiang, Kunfu Zhu, Christopher Green. The energy efficiency advantage of foreign-invested enterprises in China and the role of structural differences[J]. China Economic Review, 2015, 34: 225-235.

25. Shiva Hullavarad, Russell O'Hare, Ashok K. Roy. Enterprise Content Management solutions - Roadmap strategy and implementation challenges[J]. International Journal of Information Management, 2015, 35(2): 260-265. 